\title{
Production of extra-strong concrete axisymmetric products
}

\author{
Bakhridin Khasanov ${ }^{1, *}$ and Temur Mirzaev ${ }^{2}$ \\ ${ }^{1}$ Department of Technology and Organization of Hydromeliorative Works, Tashkent Institute of \\ Irrigation and Agriculture Mechanization Engineers, 100000 Tashkent, Uzbekistan \\ ${ }^{2}$ Academic Lyceum "INTERNATIONAL HOUSE TASHKENT", Tashkent Institute of Irrigation and \\ Agriculture Mechanization Engineers, 100000 Tashkent, Uzbekistan
}

\begin{abstract}
The article presents the results of many years of comprehensive research on the new technology of forming extra-strong unreinforced pipes for hydro-engineering construction by vibro-peristaltic hyper-compacting with simultaneous modifying of the concrete mixtures and concrete itself. The regularities of occurrence of a compacted mixture in a column of highintensity compression and tension zones varying in time, as well as the placement and configuration of the filtration fields of the formwork forms, taking into account the type and diameter of the holes preventing their blockage in the molding process, are given. As a result of experimental theoretical and industrial research, the scientific basis for the production of highly durable concrete has been developed. Technological bases of its production in axisymmetric products, as well as a new installation for molding concrete unreinforced pipes by vibro-peristaltic pressing, which is protected by copyright certificate and patent of the Republic of Uzbekistan. The installation is intended for forming low-pressure and free-flow pipes with a nominal diameter from 500 to $1500 \mathrm{~mm}$ and a length of up to 2000 $\mathrm{mm}$. The purpose of this article is to share the results of research, experience to accelerate the widespread introduction of new technology.
\end{abstract}

\section{Introduction}

The development of water management and road construction in Uzbekistan and Central Asia is associated with an increase in the need for low-pressure and pressure-free axisymmetric products. Nowadays, reinforced concrete and steel pipes are widely used, and, in such communications, where less resource-intensive non-metallic products can be used. Of all types of nonmetallic axisymmetric products, the most economical can be concrete, differing from asbestos-cement ecological purity, and compared to reinforced concrete ones, they can be very durable, both due to the absence of reinforcement subject to corrosion, and due to more dense packing of structural units of the concrete mix during compaction.

The limited number of manufactured and used concrete axisymmetric products is explained by the fact that the resistance of concrete to tensile stresses is insignificant and

\footnotetext{
* Corresponding author: mr.bakhridin@mail.ru
} 
amounts to only $5 \ldots 10 \%$ of the strength of concrete under compression. The issue of increasing the strength of concrete under tension has received little attention. The solution to this problem comes up against the basic contradiction of concrete technology:

- in order to increase the tensile strength of concrete, a worldwide reduction of W / C up to values close to the normal density of the cement paste is necessary, while at the same time limiting the consumption of cement;

- in order to increase the workability of the concrete mix, the opposite condition is necessary - an increase in $\mathrm{W} / \mathrm{C}$, an increase in water consumption, and consequently, cement consumption.

The development of the scientific foundations of extra-strong concrete technology suitable for non-reinforced axisymmetric products is possible by comprehensively resolving the listed contradictions. To solve this, it was necessary to adopt the following initial provisions of the developed technology of extra-strong concrete in molded products;

1. The properties of the concrete mixture should be determined by the technological conditions of molding products.

2. The composition of the concrete is determined by the specified design properties of the material in the product and, if necessary, may differ from the initial composition of the concrete mix.

3. The process of hyper-compacting the concrete of the molded product must ensure the obtaining of an extremely dense structure of the material, especially in the surface layers of the product.

Analysis of existing methods of modification and compaction of concrete mix in the manufacture of axisymmetric products, as well as long-term studies have shown that the most effective is the peristaltic principle of vibro-impact hyper-compaction, which also provides a deep modification of the concrete mix and concrete due to the extraction of excess mixing water and entrained air.

\section{Methods}

The main production operations of concrete and reinforced concrete products are laying, molding and compaction of the concrete mix. The most difficult process is the compaction of the mixture to the required density, which is performed by tamping, vibrating, pressing, vacuuming, centrifuging and combined methods. [3, 4, 5, 6, 7, 8, 9]. Studies of the above methods show that currently there are no highly efficient and reliable methods for modifying concrete mix and concrete. From our point of view, it is possible to increase concrete strength, especially its tensile strength, by creating a new direction for modifying concrete mix and concrete. As an analogue of highly effective modification of concrete, it is possible to choose a combination of vacuum and pressure treatment of the concrete mix. In this case, it is advisable to develop a highly efficient modifying technology, which allows to obtain extra-strong concretes on ordinary cements and local aggregates [10].

The effectiveness of increasing the strength of concrete is confirmed by numerous experimental data. So, for example, according to the data of $[11,12]$ the use of extra-strong concrete for the construction of multi-storey buildings allows reducing the metal consumption by $15 \ldots 20 \%$, labor costs by $30 \ldots 60 \%$ and production costs by $20 \ldots 30 \%$. A significant effect is achieved when using reinforced concrete for the manufacture of pipes, tanks $[13,14]$, in bridge engineering $[15,16]$.

The combination of various methods of compaction of concrete mix can dramatically increase the strength of concrete. For example, with a tensile strength of up to $80 \mathrm{MPa}$ with improved deformative characteristics $[17,18,19]$. The foregoing suggests the possibility of developing a combined technology for the production of extra-strong concrete. It is obvious that vibropressing methods must be supplemented with modification of the concrete mix 
due to the removal of excess mixing water and, especially, the gas phase of the material being molded.

\section{Results}

As a result of laboratory and production research, a new technology has been developed for the manufacture of axisymmetric products by vibro-peristaltic hyper-compaction on a special installation [20,21], shown in Fig.1. The installation is intended for forming nonpressure and low-pressure non-reinforced pipes with a diameter of 500 to $1500 \mathrm{~mm}$ and other axisymmetric products. Pipe molding can be performed at the factory and field conditions, in open areas, as well as in temporary premises. The design of the installation involves the use of several jointly operating technological principles: - modification of the concrete mixture by squeezing excess mixing water;

- limiting compaction of the material to be molded due to the crimping of the concrete mix, intensively moving with a peristaltic shock-pressing wave;

- the possibility of combining the tangential and normal efforts of the vibro-impact hyperfluid compaction, which provides the ultimate packaging of the concrete structure [21].

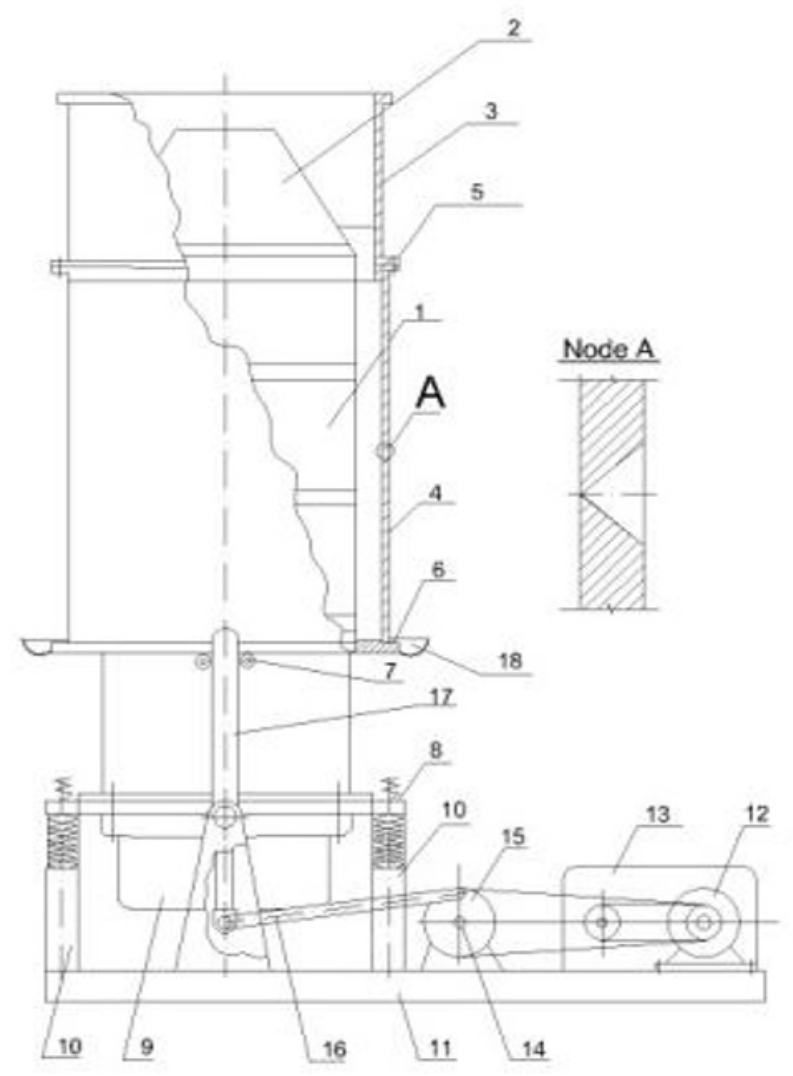

Fig 1. Scheme of pilot plant 


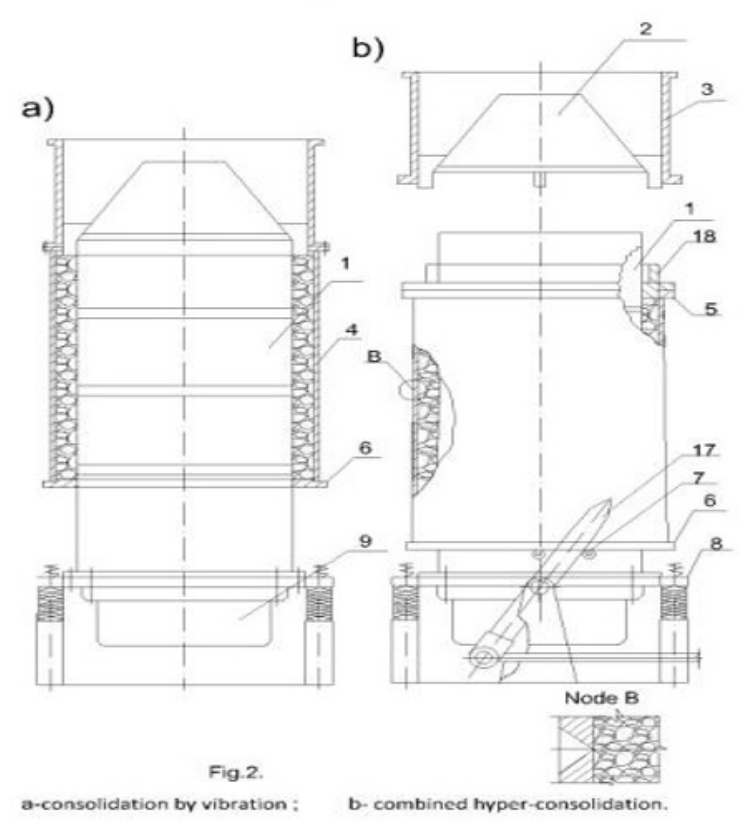

Fig 2. Vibro-peristaltic hypercompaction of concrete axisymmetric products

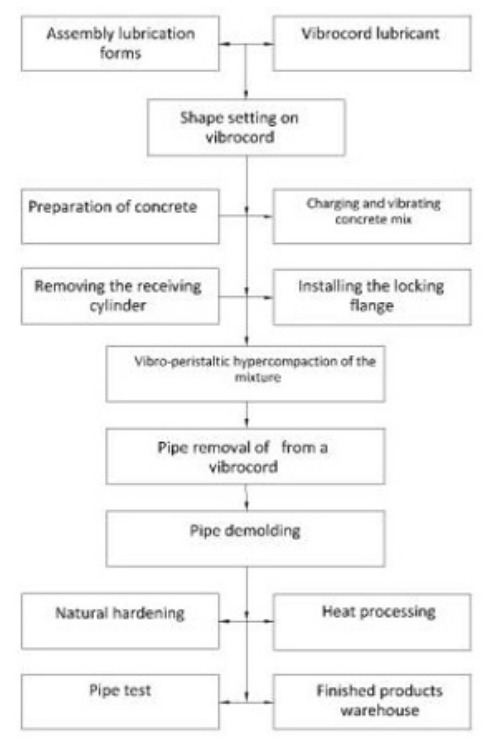

Fig 3. Technological scheme for the manufacture of concrete axisymmetric products by the method of vibro-peristaltic hyper-compaction

The installation includes a multistage vibrating core 1 (Fig. 1), which has sections with variable angles of taper, (pressure bands). The dimensions of the core, depending on the diameter, the length of the pipes being molded and the required degree of compaction of the concrete, are determined from the graph 1 in fig. 1 "a" [21]. A guide point 2 is mounted on the vibrating core 1 , fixed in the receiving cylinder 3 for the concrete mix. The receiving cylinder 3 and the outer form 4 are fastened using a calibrated flange 5 and the pallet 6 . The 
pallet is provided with rollers 7 , which provide the possibility of reciprocating movements of the form 4 relative to the vibrating core 1 . Vibration core 1 together with the vibrating plate 8 and the set of vibrators 9 rests on the stands 10. Vibrators create vertical-directional vibrations with an amplitude of $2.0 \quad \ldots \quad 3.0 \quad \mathrm{~mm}$ and a frequency of $50 \mathrm{~Hz}$.

The outer perforated form 4, made in the form of a cylinder with a longitudinal slit, which provides the dismantling of a freshly molded product, moves vertically along the core with a certain design gap. In accordance with the developed principles of providing the necessary drainage of molded concrete over the entire surface of the form 4, open filtration conic holes are made (node A, Fig. 1., and node B in Fig. 2. on the conical surface of the vibrating core).

On the base plate 11 there is an electric drive for reciprocating rotary movements of the outer form 4, which consists of an electric motor 12 with a gearbox 13 , connected by a chain transmission to the shaft 14 . On the shaft 14 two pulleys 15 are connected, pivotally connected to the rods 16 , which allow the outer form to move with using pushers 17 . The upper cylindrical part of the vibrating heart 1 is additionally equipped with a vibrator (IV107), which informs the core of horizontal-circular oscillations with an amplitude of $0.6 \ldots$ $0.8 \mathrm{~mm}$ and a frequency of $50 \mathrm{~Hz}$.

General installation characteristics are shown below.

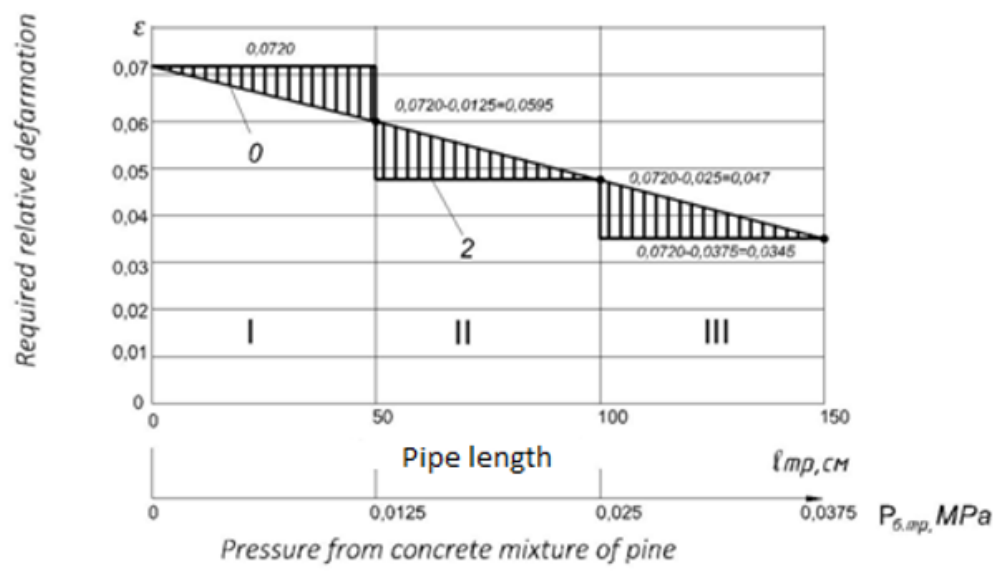

Fig 4. Relationships of relative deformation on pipe length

1 - the effect of the height of the mixture column on the required relative deformation;

2-relative deformation of concrete pipe walls from vibro-peristaltic pressing.

\section{Technical characteristics of the installation}

1. Productivity, pipes per shift .................... 25 ... 35pcs.

2. Frequency of reciprocating movements. outer form .... $251 / \mathrm{min}$.

3. Overall dimensions in the manufacture of pipes

with a diameter of $1000 \mathrm{~mm}$ and a length of $1500 \mathrm{~mm}$ :

length, $\mathrm{mm}$ 2700

width, $\mathrm{mm}$ 1800

height, $\mathrm{mm}$.................... 3300

4. Mass of installation, $t$ 3.85

5. Installed power, $\mathrm{kW}$ 


\section{Technological modes of pipe formation}

The technological process (Fig. 3) of forming concrete pipes begins with the delivery of a portion $(0.83 \mathrm{~m} 3)$ of the concrete mix to the receiving cylinder 3 (Fig. 1., Fig. 2) of the installation [21]. For molding, the optimum composition of the concrete mix is 1: 0.85 : 2.89 , for В / Ц - 0.32 (cement consumption $480 \mathrm{~kg} / \mathrm{m} 3$ ). Filling the annular cavity of the installation with concrete mix is carried out with simultaneous operation of all vibrators for 1.0 ... 2.0 minutes. During this time, the mixture is pre-compacted from the joint effect of vertical-directional and horizontal-circular oscillations created by simultaneously working upper and lower vibrators.

The compaction process is accompanied by the removal of part of the excess mixing water and entrained air when the concrete is filled with the mold. Removal of the gas phase occurs under the action of gravity of the upper layers of the concrete mix and the efforts created by the vibrator pack, which contributes to the formation and significant compaction of the structure of the molded product. This completes the process of filling the annular space and pre-compacting the concrete (Fig. 2 "a"). Then separates the receiving cylinder 3 from the installation form and replaces it with a fixing-blocking flange 18. The concrete mix is fed in, the removal cylinder is removed and the flange 18 is installed within $0 \ldots 5$ minutes using an electric hoist controlled from the molding station. As seen in fig. 2 "b", the preformed concrete pipe is allowed to move freely along the axis of the vibrating core 1 . Usually this movement does not occur due to the combined effect of three factors:

- the presence of the taper of the core in its middle part (Fig. 2 "a");

- a relatively high density of concrete partially molded pipe;

- The effects of significant adhesion forces between the concrete and the conical surface of the core 1 , as well as the inner perforated surface of the outer form 4 .

The main process of forming the structure of extra-strong concrete in the pipe walls begins with the use of the second stage of peristaltic hyper-consolidation. This hypercompaction begins with the re-activation of all vibrators and the electric drive, providing reciprocating movement of the outer form. Under the action of the gravity of the concrete of the forming pipe and the mass of the form, the outer form is slowly moving with the material down. When the shape is shifted, the body of the molded concrete moves past three artificial narrowing sections in the direction of the increasing taper of the core. Such movement of the formable pipe causes the formation in the body of the formable product of three parallel intense waves of hyper-consolidation. At the same time, in the zone of moving waves of hyperdensification, shock-pressing and horizontally-shifting efforts arise to form an extremely dense concrete structure [21].

With additional, highly efficient hyper-compacting, the residual part of the excess mixing water is removed. By the end of the molding process, the viscous-plastic part of the concrete structure (cement paste) in terms of W / C becomes close to the "normal density" cement paste. Consequently, the concrete of the formed pipe is distinguished by the greatest possible density and, accordingly, its ultimate strength. This is facilitated by the optimal packaging of the constituent concrete as a result of the use of reciprocating movements of the outer form with the product relative to the surface of the vibrating core. These movements provide the greatest stability of the particles of the aggregate and the effect of "grinding" the inner surface of the forming pipe. The grout effect is accompanied by the most compact placement of coarse aggregate particles, while at the same time providing a high-density surface layer with a very smooth surface. The process of forming a pipe ends at the time of the termination of the vertical displacement of the form together with a freshly made pipe. This occurs when the pallet reaches the shape of a vibrating plate or in 
the case of the ultimate compaction of concrete, which is accompanied by the hang of the entire shape on the surface of the vibrating core.

The uniformity of compaction of concrete over the height of a vertically formed pipe is fully ensured by the reciprocating movement of the outer form, ensuring the equalization of the pressure gradient over the entire volume of concrete during $4 \ldots 5$ minutes of molding. The reciprocating movement of the form also contributes to the release of the molded concrete pipe from the vibrating core 1, after the extrusion of its walls. The form with the product is extracted with the help of an electric hoist and transferred to the dismantling station.

The outer form is exempt from the product and the technological cycle is repeated. The total duration of the concrete pipe manufacturing cycle is $10 \ldots 15$ minutes. The maturation of the produced pipes occurs during the optimal period of heat treatment by using factory steaming chambers or the heat of solar radiation (under transparent films).

\section{Discussions}

A large number of works by native and foreign researchers are devoted to the scientific substantiation of the technology for producing extra-strong concretes, but the solution to this problem is far from completion $[5,6,7,11,12,13,14,15]$.

The production of extra-strong unreinforced products is associated primarily with the maximum use of the potential strength properties of cement, aggregates and concrete, determined by the degree of their compaction and release of excess mixed water, as well as entrained air $[5,7,16,17,19]$.

Vibro-shock-peristaltic pressing with simultaneous modification of the concrete mix during the molding process provides an intensive increase in the strength of concrete in the initial period of hardening, reducing the duration of heat treatment, and in the natural conditions of Central Asia - its complete elimination, saving about $100 \mathrm{~kg}$ of steel bars per $1 \mathrm{cu}$. pipe meter, the manufacture of products with immediate dismantling, increasing water resistance, frost resistance, aggressiveness and durability of structures [21].

\section{Conclusions}

1. The technological foundations of the formation of axisymmetric non-reinforced products, in replacement of reinforced concrete, from modified concrete mix and hypercompact concrete have been developed with the help of a special installation protected by copyright certificate and patent of the Republic of Uzbekistan [1,2].

2. A set of completed studies established the patterns of placement and configuration and filtration fields of the concrete form. Proved the need to change the pitch of the filtration holes in the height of the molded products.

3. We studied the clogging of the filtering holes and found the optimal shape and diameter to prevent clogging. The geometry of the through holes with the angle alpha from 600 to 1300 was investigated.

4. The law of the distribution of peristaltic waves of hyper-strength over the thickness and length of the molded products was investigated, with the foundations of the sedimentation of concrete in the area of pressing bands, which determined the boundaries of changes in the initial and residual values of $\mathrm{W} / \mathrm{C}$.

5. With the relative simplicity and reliability of the installation design, its operation allows the molding, hyper-consolidation and extraction of excess mixing water in 7-10 minutes. 
For the first time in the installation, vibro-impact, peristaltic and shear (reciprocating) deformations of the mixture are combined to provide the maximum level of hyperconsolidation.

We express our deep gratitude to the leadership of the Kuyluk Experimental Plant of Bridge Reinforced Concrete Structures in the city of Tashkent for their assistance in conducting experimental-production studies.

\section{References}

1. A.Y. Sayganov, B.B. Khasanov, The equipment for concentrate mixture preparation. Certificate of authorship 1357239, «Ed.Invented», N 45. (1987).

2. A.Y. Sayganov, B.B. Khasanov, The Equipment for manufacturing of pipe like products, Patent № 1636, (1995)

3. V.I. Melikhov, A.G. Grayver, Manufacturing of reinforced concentrate by radial pressing, pp. 61. (1981)

4. S.A. Osmakov, F.G. Braude, Concentrate molding machine by shock-vibration. L.: Ed. pp.128 (1976).

5. A.P. Popov, A.L. Tsionskiy, V.A. Khripunov, Manufacturing of reinforced concentrate by vibrohydropressing pipes, M.: Ed., pp. 273. (1979).

6. O.A. Savinov, E.V. Lavrinovich, Vibrotechnique of compaction and the formation of concrete mixture, L: Ed., pp. 280 (1986).

7. N.A. Storojuk, Mechanizm drawing of concrete mixture by vacuum. Ed. Higher Educational Institutions, Building and Architecture. N 2. pp. 72-76,(1979).

8. I.I. Ovchinnikov, I.G. Ovchinnikov, G.V. Chesnokov, E.S.Mikhaldykin, O probleme rascheta trubobetonnykh konstruktsiy s obolochkoy iz raznykh materialov. Chast' 1. Opyt primenenia trubobetona s metallicheskoy obolochkoy // Internet-zhurnal , 5, s. 120 (2015).

9. L.I. Storozhenko, D.A. Ermolenko, O.I. Lapenko, Trubobeton. - Poltava : TOB ASMG, 306 s. (2010)

10. B.B. Khasanov, Concrete mixture modification inpressing process. Resource saving technology of concrete mixture on transport and hydrotechnics building: Intercollegiate union of science, Dnepopetrovsk, Ed. 1,pp. 17-18. (1995).

11. O.M. Popkova, Prefabricated reinforced concrete structures of multi-storey buildings. International experience, Review information. Building materials. Ed. 7 pp. 65,(1980).

12. I.A. Duvanova, I.D. Sal'manov, Trubobetonnye kolonny v stroitel'stve vysotnykh zdaniy i sooruzheniy // Stroitel'stvo unikal'nykh zdaniy i sooruzheniy. No. 6(21), s/ 89-103 (2014)/

13. A.G. Vandalovskiy, D.A. Uchingus, G.A. Ulitina, Concrete pipes of rotation pressing, Concrete and reinforced mixtures. N 12, pp. 15-16(1979).

14. N.P. Bleshik, Basis of pressing theory and vacuuming of concrete mixture, Technology of non-vibration formation of reinforced mixture products.Minsk, pp. 45-49.(1979)

15. A.S. Lukyanov, A.A. Grayfer, Manufacturing of reinforced pipes with diameter 800$1200 \mathrm{~mm}$ by radial pressing, Industry of reinforced mixture, series 3, ed. 4. M.: pp. 913.(1980)

16. N.P. Bleshik Structural and mechanical options and theology of concrete mixture and pressed vacuum mixture, Minsk: «Science and technology» pp. 232(1977)

17. V.P. Mitrofanov, A.N. Dergam, Posobie po raschetu prochnosti trubobetonnykh elementov pri osevom szhatii : Monografiya. Poltava: PoltNTU im. Yuriya Kondratyuka, 91 s. (2008) 
18. I.M. Garanzha, About approaches to the calculation of composite tubes in Ukraine and abroad// Metal constructions. Vol. 20, No. 1, p.45-53 (2014).

19. B.B. Khasanov, V.N. Punagin, Technology of extra-strong mixture under the manufacturing of reinforced pipes by vibro-shocking unreinforced mixtures Architecture and Building of Uzbekistan, Tashkent. N 6. pp. 35-37. (1988)

20. V.N. Punagin, B.B. Khasanov, New hyper density of concrete pipes for hydromeliorative building. Anniversary collection of Belgorod State Technical Academy of building materials, Belgorod, pp 22-23. (1995)

21. B.B. Khsasanov Theoretical and Experimental basics of concrete pipe manufacturing on vibro-shocking technology. Tashkent. «Labor», pp. 187. (1996) 